\title{
Correction: Rydén et al. Physiological and Clinical Responses in Pigs in Relation to Plasma Concentrations during Anesthesia with Dexmedetomidine, Tiletamine, Zolazepam, and Butorphanol. Animals 2021, 11, 1482
}

\author{
Anneli Rydén *, Marianne Jensen-Waern, Görel Nyman and Lena Olsén (D)
}

check for

updates

Citation: Rydén, A.; Jensen-Waern, M.; Nyman, G.; Olsén, L. Correction: Rydén et al. Physiological and Clinical Responses in Pigs in Relation to Plasma Concentrations during Anesthesia with Dexmedetomidine, Tiletamine, Zolazepam, and Butorphanol. Animals 2021, 11, 1482. Animals 2021, 11, 3474. https:// doi.org/10.3390/ani11123474

Received: 28 October 2021 Accepted: 16 November 2021 Published: 6 December 2021

Publisher's Note: MDPI stays neutral with regard to jurisdictional claims in published maps and institutional affiliations.

Copyright: (c) 2021 by the authors. Licensee MDPI, Basel, Switzerland. This article is an open access article distributed under the terms and conditions of the Creative Commons Attribution (CC BY) license (https:// creativecommons.org/licenses/by/ $4.0 /)$.
Department of Clinical Sciences, Swedish University of Agricultural Sciences, SE-750 07 Uppsala, Sweden; marianne.jensen-waern@slu.se (M.J.-W.); gorel.nyman@slu.se (G.N.); lena.olsen@slu.se (L.O.)

* Correspondence: anneli.ryden@slu.se

\section{Text Correction}

There were several errors in the original article [1]:

1. In the sixth line of the abstract, instead of "The anesthesia was induced by an intramuscular injection of dexmedetomidine, tiletamine zolazepam, and butorphanol in 12 pigs". It should be "The anesthesia was induced by an intramuscular injection of dexmedetomidine, tiletamine-zolazepam, and butorphanol in 12 pigs".

2. In Section 3.3, on page 6, instead of "In all pigs, the average Cmax for all drugs was 12 (range 10-13) after administration of the IM induction drug combination", it should be "In all pigs, the average Cmax for all drugs was reached 12 (range 10-13) min after administration of the IM induction drug combination".

3. In Section 3.3, on the bottom line of page 6, instead of "IV (Table 2)", it should be "IV (Figure 2)".

\section{Figure/Table Legend}

In the original article, there were mistakes in the legend for Table 3 and Figure 2. The correct legends appears below.

Table 3. Drug analysis data.

Figure 2. Profiles of log plasma concentrations for each drug over time for short-term anesthesia induced by intramuscular administration of dexmedetomidine $0.025 \mathrm{mg} / \mathrm{kg}$, tiletamine $2.5 \mathrm{mg} / \mathrm{kg}$, zolazepam $2.5 \mathrm{mg} / \mathrm{kg}$, and butorphanol $0.1 \mathrm{mg} / \mathrm{kg}$ in pigs $(n=7)$. Group $S$ (dotted lines $n=3$ ) received a single dose at time zero. Group R (solid lines $n=4$ ) also received one-third of the initial dose intravenously at $60 \mathrm{~min}$. Time to first spontaneous movement is indicated with a dotted arrow for Group S and a solid arrow for Group R.

\section{Error in Table}

In the original article, there was a mistake in Tables 2 and 4 as published.

1. On page 8 , in the third line of the footer of Table 4, instead of "and group Ralso", it should be "and group $\mathrm{R}$ also".

2. The footnote under Table 4 should be placed under Table 2.

The corrected Tables 2 and 4 appear below. The authors apologize for any inconvenience caused and state that the scientific conclusions are unaffected. The original article has been updated. 
Table 2. Observed clinical responses in relation to plasma concentrations.

\begin{tabular}{|c|c|c|c|c|c|c|}
\hline \multirow{3}{*}{ Noted Observations } & & & \multicolumn{4}{|c|}{ Concentration Range $(\mathrm{ng} / \mathrm{mL})$ Group $S$ and $R$} \\
\hline & \multicolumn{2}{|c|}{$\begin{array}{l}\text { Time (min) from } \\
\text { Injection (IM) }\end{array}$} & \multirow{2}{*}{ Dexmedetomidine } & \multirow{2}{*}{ Tiletamine } & \multirow{2}{*}{ Zolazepam } & \multirow{2}{*}{ Butorphanol } \\
\hline & S & $\mathbf{R}$ & & & & \\
\hline Lateral recumbency & \multicolumn{2}{|c|}{$2-4$} & $<1.59-3.56$ & $<126-268$ & $<106-789$ & $<5.22-15.60$ \\
\hline Unconsciousness & \multicolumn{2}{|c|}{$5-15$} & $1.99-6.00$ & $169-337$ & $737-1330$ & $8.86-19.20$ \\
\hline $\begin{array}{l}\text { Last sample before response to } \\
\text { noxious stimulus }\end{array}$ & $60-120$ & 120 & $2.01-3.48$ & $115-158$ & $520-1180$ & $6.74-11.60$ \\
\hline Palpebral reflexes & $60-70$ & $126-180$ & $1.69-2.38$ & $101-129$ & $525-782$ & $6.80-10.50$ \\
\hline Response to noxious stimulus & $70-140$ & $126-180$ & $1.69-2.38$ & $101-129$ & $525-782$ & $6.80-10.50$ \\
\hline First movement & $70-140$ & $126-180$ & $1.69-1.97$ & $106-123$ & $444-713$ & $6.47-9.42$ \\
\hline Standing & $120-180$ & $175-240$ & $1.14-2.01$ & $73.7-109$ & $250-678$ & $4.74-8.70$ \\
\hline
\end{tabular}

Time range in min and the corresponding plasma concentration range for each drug and noted observation during the short-term anesthesia induced by dexmedetomidine $0.025 \mathrm{mg} / \mathrm{kg}$, tiletamine $2.5 \mathrm{mg} / \mathrm{kg}$, zolazepam $2.5 \mathrm{mg} / \mathrm{kg}$, and butorphanol $0.1 \mathrm{mg} / \mathrm{kg}$ after intramuscular (IM) administration in growing pigs single $(\mathrm{S})(n=6)$ and repeated $(\mathrm{R})(n=6)$. All pigs received a single dose at time zero, and group $\mathrm{R}$ also received one-third of the initial dose intravenously at $60 \mathrm{~min}$. All blood samples were taken in relation to the noted observation except for lateral recumbency, which was taken at 5 min after induction. Plasma concentrations were available for seven pigs.

Table 4. Pharmacokinetic parameters.

\begin{tabular}{|c|c|c|c|c|c|c|}
\hline & \multicolumn{3}{|c|}{ IM Group S $(n=3)$} & \multicolumn{3}{|c|}{ IV Group R $(n=4)$} \\
\hline & $t_{1 / 2}(\min )$ & $t_{\max }(\min )$ & $\mathrm{C}_{\max }(\mathrm{ng} / \mathrm{L})$ & $t_{1 / 2}(\min )$ & cI (L/kg/min) & $\mathrm{Vd}(\mathrm{L} / \mathrm{kg})$ \\
\hline Dexmedetomidine & $125 \pm 37$ & $13 \pm 3$ & $5.6 \pm 3.2$ & $117 \pm 24$ & $0.012 \pm 0.004$ & $1.7 \pm 0.5$ \\
\hline Tiletamine & $90 \pm 12$ & $10 \pm 5$ & $342 \pm 152$ & $80 \pm 13$ & $0.050 \pm 0.010$ & $5.8 \pm 0.9$ \\
\hline Zolazepam & $72 \pm 6$ & $12 \pm 3$ & $1372 \pm 438$ & $76 \pm 13$ & $0.009 \pm 0.002$ & $1.0 \pm 0.2$ \\
\hline Butorphanol & $97 \pm 11$ & $13 \pm 3$ & $21 \pm 9$ & $101 \pm 16$ & $0.012 \pm 0.002$ & $1.6 \pm 0.4$ \\
\hline
\end{tabular}

We apologize for any inconvenience caused to the readers by this change. The change does not affect the scientific results. The original article has been updated.

\section{Reference}

1. Rydén, A.; Jensen-Waern, M.; Nyman, G.; Olsén, L. Physiological and Clinical Responses in Pigs in Relation to Plasma Concentrations during Anesthesia with Dexmedetomidine, Tiletamine, Zolazepam, and Butorphanol. Animals 2021, 11, 1482. [CrossRef] 